\title{
DESCRIPCIÓN DE LOS MACHOS DE PELTIDIUM NICHOLLSI \\ GEDDES, 1968 Y PELTIDIUM PROXIMUS VARELA, 2005 \\ (COPEPODA: HARPACTICOIDA: PELTIDIIDAE)
}

\author{
Carlos Varela \\ Acuario Nacional de Cuba, Calle 1ra \#6002 e/e 60 y 62, C. P. 11300, Playa, Ciudad de La Habana, Cuba. \\ varela06@gmail.com
}

\section{RESUMEN}

Los machos de Peltidium nichollsi y P. proximus se describen por primera vez. Además, esta es la primera cita de $P$. nichollsi para aguas cubanas.

Palabras clave: Copepoda, Harpacticoida, Peltidiidae, Peltidium.

\section{ABSTRACT}

The male of Peltidium nichollsi and P. proximus are described for the first time. Also, this is the first record of $P$. nichollsi for cuban waters.

Keywords: Copepoda, Harpacticoida, Peltidiidae, Peltidium.

\section{INTRODUCCIÓN}

En colectas efectuadas en Playa Baracoa, localidad ubicada al oeste de la provincia de Ciudad de La Habana, se colectaron varios ejemplares de copépodos pertenecientes al género Peltidium Philippi, 1839. Luego de su estudio se concluyó que ambos coinciden con dos especies de las cuales el macho de las mismas aún se desconoce.

Geddes (1968), describe a Peltidium nichollsi de una hembra ovígera colectada en Las Bahamas, mientras que Varela (2005), describe a P. proximus de 4 hembras, 2 de ellas ovígeras, siendo los machos de ambas especies desconocidos hasta el momento. Por lo anterior, en el presente trabajo se describen por primera vez los machos de estas dos especies. Además, Peltidium nichollsi se registra por primera vez para Cuba.

\section{MATERIALES Y MÉTODOS}

La colecta fue realizada mediante buceo en apnea. Se tomaron macroalgas del fondo y se introdujeron en una bolsa de polietileno, cuyo contenido fue posteriormente tamizado y fijado. Los copépodos se separaron bajo el microscopio estereoscópico. El material estudiado se encuentra depositado en Departamento de Colecciones Naturales Marinas del Acuario Nacional de Cuba.

\section{RESULTADOS}

\section{TAXONOMÍA}

Peltidium nichollsi Geddes, 1968

Primer registro para Cuba

(Fig. 1, A-C)

Material estudiado. Macho adulto. Colectado en Playa Baracoa, provincia de La Habana, 14. VIII. 2005. Fondo rocoso con macroalgas a $15 \mathrm{~m}$ de profundidad. ANC 07.2.1.1.015. 


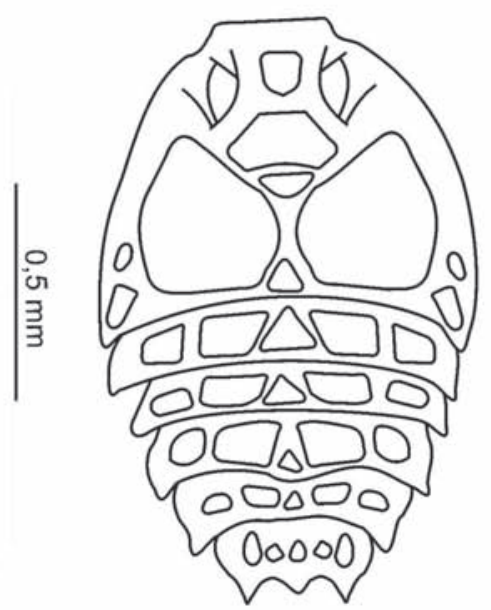

A

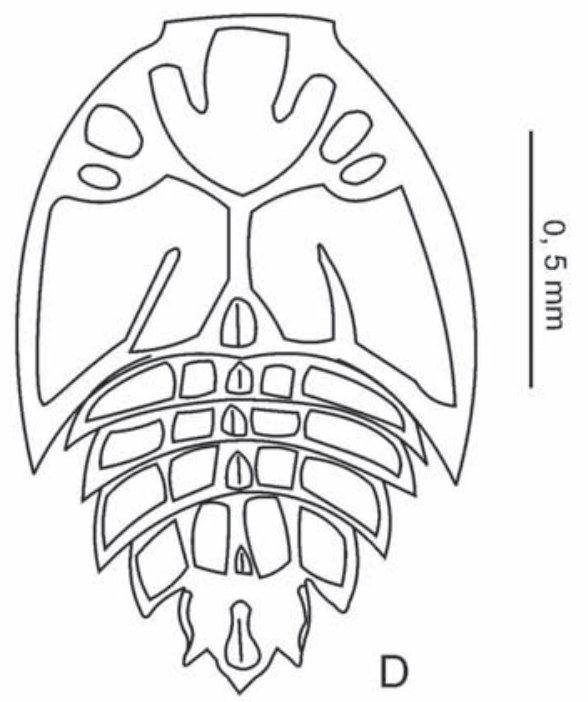

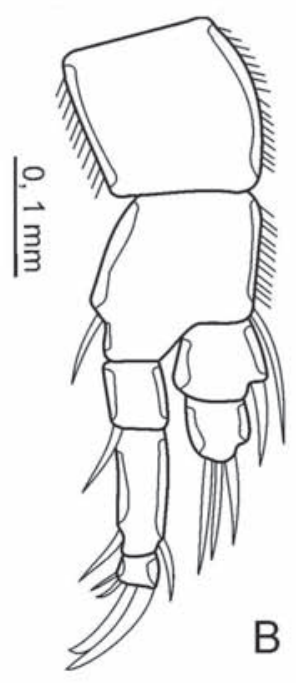

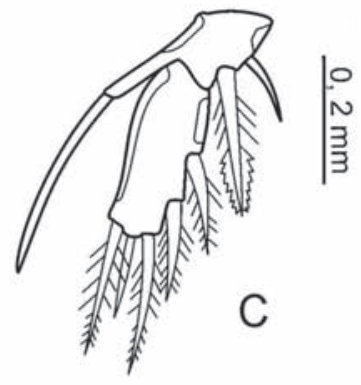

B

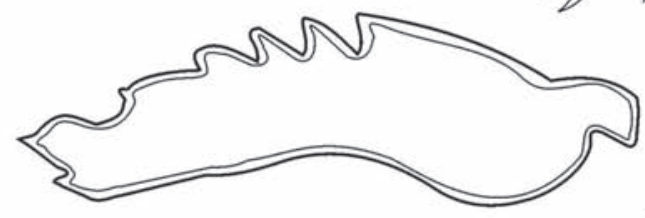

$\mathrm{F}$

Figura 1. Peltidium nichollsi. A. Vista dorsal. B. Pata 1 y C. Pata 5. Peltidium proximus. D. Vista dorsal. E. Pata 1 y F. Vista lateral (sin marcas dorsales). 
Descripción. Cuerpo aplanado dorsoventralmente. Rostro amplio, dirigido ventralmente (Fig. 1A). Segmentos abdominales retraídos, no observables en vista dorsal. Rama caudal con 6 setas. Anténula con 7 artejos, estetasco en el artejo 4. Exopodito de la antena con 2 artejos, artejo 1 con una seta y artejo 2 con 3, una de ellas pectinada. Endopodito con 2 artejos. Maxílula con 2 enditos, con 2 y 3 setas. Maxila con 2 enditos con 1 y 3 setas; basoendopodito con una garra terminal. Endopodito del maxilípedo ovoide, con una garra fuerte que es 2/3 del largo del endopodito. Mandíbula con palpo mandibular de 2 artejos. Pata 1 con coxopodito casi tan largo como ancho, basipodito con 2 setas, una en el borde interno y otra en el externo. Exopodito con 3 artejos, artejo 2 es el más largo de los 3, con 2 setas, una en el borde interior y otra en el exterior; artejo 3 con 2 setas y 2 garras distales. Endopodito con 2 artejos, artejo 1 con una seta en su borde interno, artejo 2 con 3 setas, las 2 distales más largas que el artejo (Fig. 1B). Basiendopodito de la pata 5 con 3 setas, borde externo con una seta. Exopodito más largo que ancho con 5 setas (Fig.1C).

\begin{tabular}{|lll|}
\hline & Exopodito & Endopodito \\
\hline P2 & $1 ; 1 ; 2,2,3$ & $1 ; 2 ; 1,2,0$ \\
P3 & $1 ; 1 ; 3,2,3$ & $1 ; 2 ; 3,2,0$ \\
P4 & $1 ; 1 ; 3,2,3$ & $1 ; 2 ; 2,2,0$ \\
\hline
\end{tabular}

Peltidium proximus Varela, 2005

(Fig. 1, D-F)

Material examinado. Macho adulto. Colectado en Playa Baracoa, provincia de La Habana, 14. VIII. 2005. Fondo rocoso con macroalgas a $15 \mathrm{~m}$ de profundidad. ANC 07.2. 1. 1. 013.

Descripción. Cuerpo aplanado dorsoventralmente (Fig. 1D). Epímeros del cefalotórax casi alcanzan la mitad del segmento 3. Los segmentos del 2 al 5 son más estrechos que el cefalotórax. Rostro amplio, dirigido ventralmente. Segmentos abdominales retraídos, no observables en vista dorsal. Sobre el cefalotórax y los siguientes segmentos aparece una cresta mediodorsal prominente (Fig. 1F). Rama caudal con 6 setas. Anténula con 7 artejos, 3 y 4 con estetascos. Exopodito de la antena con 2 artejos, artejo 1 con 1 seta y artejo 2 con 3 setas. Endopodito con 3 artejos, artejo 1 con 1 setas, artejo 2 con 3 y artejo 3 con 7. En su borde interno cerca del extremo distal tiene 2 ganchos. Mandíbula con palpo mandibular de 2 artejos. Maxílula con 2 enditos con 2 y 4 setas respectivamente. Maxila con 3 enditos con 2, 1 y 3 setas respectivamente. Basipodito termina en un proceso en forma de gancho. Endopodito del maxilípedo más largo que ancho con una garra curvada con una seta en su base. Pata 1 con coxopodito alargado, basipodito con 2 setas, una en el borde interno y otra en el externo. Exopodito con 3 artejos, artejo 2 es el mas largo de los 3 con 2 setas en el borde interior y otra en el exterior; artejo 3 con 2 setas y 2 garras distales. Endopodito con 2 artejos, artejo 1 con una seta en su borde interno, artejo 2 con 3 setas, las 2 distales más largas que el artejo (Fig. 1E). Basoendopodito de la pata 5 reducido con 2 setas, borde externo con una seta. Exopodito más largo que ancho, con espinas fuertes.

\begin{tabular}{|lll|}
\hline & Exopodito & Endopodito \\
P2 & $1 ; 1 ; 2,2,3$ & $1 ; 2 ; 1,2,0$ \\
\hline P3 & $1 ; 1 ; 3,2,3$ & $1 ; 2 ; 2,2,0$ \\
\hline P4 & $1 ; 1 ; 3,2,3$ & $1 ; 2 ; 2,2,0$ \\
\hline
\end{tabular}


Comentario. El macho de P. nichollsi se diferencia de los machos de las restantes especies por poseer una de las setas pectinada en el artejo 2 del exopodito de la antena y basiendopodito de la pata 5 con 3 setas, borde externo con una seta. Exopodito más largo que ancho con 5 setas. Mientras que $P$. proximus se diferencia por presentar los epímeros del cefalotórax que casi alcanzan la mitad del segmento 3, el maxilípedo presenta dos grupos de setas en el basipodito y la cresta dorsal del segmento genital sobrepasa la longitud de los epímeros.

\section{AGRADECIMIENTOS}

A la colega Galia Varona (Department of Environmental Resources Management, U. S. A.), por la literatura facilitada. Al colega Manuel Ortiz (Centro de Investigaciones Marinas, Cuba) por sus sugerencias al trabajo.

\section{LITERATURA CITADA}

Geddes, D. C. 1968. Marine investigations in Las Bahamas. Families Porcellidiidae, Peltidiidae y Tegastidae. Sarsia 35: 9-56.

Varela, C. 2005. Especie nueva del género Peltidium (Copepoda: Harpacticoida: Peltidiidae) de aguas cubanas. Solenodon 5: 1-5. 